Article

\title{
Internal R\&D and Acquisition Performance of Chinese Pharmaceutical Firms: Moderation Effect of Acquisition Motive and Corporate Ownership
}

\author{
Qi Yue ${ }^{1}$, Xing Hua ${ }^{2, *}$ and Jianyuan $\mathrm{Li}^{1}$ \\ 1 School of Economics and Management, South China Normal University, Guangzhou 510006, China; \\ yueqi@m.scnu.edu.cn (Q.Y.); sem_scnu@163.com (J.L.) \\ 2 Department of Financing and Economics, Guangdong Youth Vocational College, Guangzhou 510545, China \\ * Correspondence: huaxing_gd@163.com
}

Received: 7 March 2019; Accepted: 13 May 2019; Published: 16 May 2019

\begin{abstract}
Although corporate capability has been recognized as a key factor affecting corporate acquisition performance, the role of R\&D capability in acquisition performance has not been fully explained. The aim of this paper was to research the impact of internal $R \& D$ on acquisition performance according to a sample of 215 acquisitions of Chinese listed pharmaceutical companies from 2012 to 2016. First, it was found that R\&D has a significant negative effect on acquisition performance. Furthermore, it was confirmed that the acquisition motive and the ownership of the acquiring firm have a moderating effect on the relationship between $R \& D$ and acquisition performance. Compared to non-technical acquisitions, the negative effect of internal $R \& D$ on acquisition performance was reduced for technical acquisitions. Compared with non-state-owned-enterprise acquisition, the negative effect of internal R\&D on the acquisition performance of state-owned enterprises was weakened. Our study enriches the research of the path dependence theory on the acquisition performance of enterprises and also the interpretation of acquisition performance on the basis of internal and external innovation and the institutional theory.
\end{abstract}

Keywords: internal R\&D; acquisition performance; acquisition motives; technical acquisition; corporate ownership

\section{Introduction}

Acquisition is one of the important ways for companies to restructure, expand production and operation channels, and achieve the goal of rapid expansion and sustainable development and is also effective in managing the current international economic situation [1,2]. Since 2009, the Chinese acquisition market has demonstrated a trend of continual growth. Especially after 2014, the number of acquisitions has seen an explosive growth, and the transaction scale has increased significantly. In 2017, the acquisition market of China had a total amount of 8016 acquisition transactions, which corresponded to 3.29 trillion yuan, and 4018 acquisition transactions were completed, which represents an increase by $34 \%$ compared to the previous year and involved an amount of 1.51 trillion yuan. However, it is extremely uncertain whether acquisitions can meet companies" expectations [3]. Considerable research has been done to explore the success or failure of acquisitions, especially about how to obtain the desired acquisition performance after a successful acquisition. Current mainstream researchers roughly consider three aspects to analyze this question: Firstly, the problem is firmly related to the characteristics of the acquiring company, including competence, scale, ownership, sector, ownership structure, acquisition experience, etc. of the acquiring company [4,5]; Secondly, it is related to the characteristics of the acquired company, including performance, business relevance, relative scale, 
and regional characteristics of the acquired company before the acquisition [6]; Thirdly, it is related to the characteristics of the acquisition transaction, including the pattern of payment during the process of acquisition and the extent of integration after the acquisition [7]. Obviously, it can be seen that the competence of a company plays an important role in affecting the acquisition performance. $R \& D$ and innovation are two of the most important components of the competence of a company. Nevertheless, although the existing research has fully explored the role of internal R\&D and innovation on corporate performance, it has not adequately investigated the relationship between R\&D and acquisition performance from the perspective of acquisition. In addition, differences in acquisition motives can lead to differences in the integration of resources, affecting the extent of acceptance and integration of the acquired company [8,9]. Meanwhile, the ownership of different enterprises contributes to the difference between the internal and external environment of an enterprise and will have a different impact on the efficiency of the enterprise's integration of resources, which may affect the relationship between internal R\&D and acquisition performance.

Based on the above literature, this study attempts to provide empirical evidence for the relationship between R\&D strategy and acquisition strategy in the pharmaceutical industry. The pharmaceutical industry occupies a very important position in national economy and future economic development planning in China. The pharmaceutical industry is an innovation-driven industry [10], so it has always been one of the industries with the largest innovation investment ratio. At the same time, the acquisition momentum of China's pharmaceutical industry is in a growing trend. Acquisitions have also been seen as one of the main ways of achieving external innovation [10-12]. Whether domestic small pharmaceutical enterprises, hospitals and chain pharmacies, or foreign pharmaceutical companies, research and development institutions and medical institutions engaged in drug discovery are commonly the target of acquisitions. A series of new medical treatments promulgated by the Chinese government have also induced Chinese pharmaceutical enterprises to increase their purchasing efforts. Under the new competition pattern, Chinese pharmaceutical enterprises are using deposited funds and market capital to integrate resources, which is setting off a wave of acquisition. However, the success rate of acquisition transactions and the integration after acquisition vary considerably. The characteristics of frequent acquisition activities, high technology content, large R\&D investment, and high environmental dynamics make China's pharmaceutical industry a particularly suitable environment to study the relationship between $R \& D$ activities and acquisition performance.

This paper selected the acquisition events of all listed pharmaceutical companies that occurred in 2012-2016 to investigate the following three questions: First, how the internal R\&D of a company affect the acquisition performance; secondly, whether the acquisition motive has a moderating effect on the relationship between internal R\&D and acquisition performance; thirdly, whether the ownership of an enterprise has a moderating effect on the relationship between internal R\&D and acquisition performance. This work can, on one hand, enrich the research on acquisition performance, especially on the impact mechanism of acquisition performance from the perspective of path dependence. On the other hand, it can enrich the research on enterprise innovation, especially on internal and external innovation methods and their synergistic effects.

\section{Review of the Pharmaceutical Industry in China}

\subsection{Market Development of the Pharmaceutical Industry in China}

The overall scale of China's pharmaceutical industry has continued to develop in recent years. As shown in Figure 1, the total sales involving China's pharmaceutical industry increased from 1733.77 billion yuan in 2012 to 2711.66 billion yuan in 2017, with an increase of $56.4 \%$. At the same time, the total revenue also grew, from 186.59 billion yuan in 2012 to 332.48 billion yuan in 2017, with an increase of $78.19 \%$. The profitability of the industry is maintained at above $10 \%$ per year. In 2017, the profitability of the industry was the highest in recent years, reaching $12.26 \%$. 


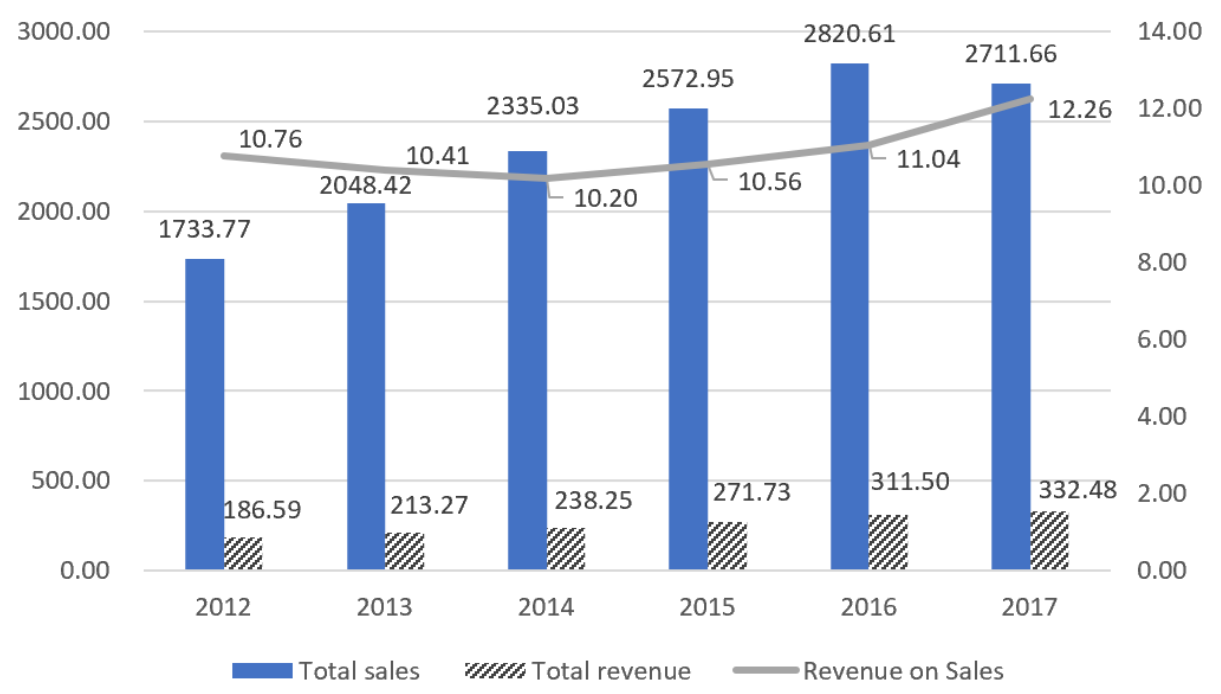

Figure 1. Sales and revenue of the pharmaceutical industry in China (billion yuan). Data resource: China National Bureau of Statistics, http://www.stats.gov.cn.

Competition in China's pharmaceutical industry is fierce, with a large number of companies. As shown in Figure 2, 2016 was the year with the largest number of operating companies, reaching 7532. From 2012 to 2017, the number of companies in the pharmaceutical industry increased by more than 1100 . Among them, about $10 \%$ of the companies could not gain profits every year.

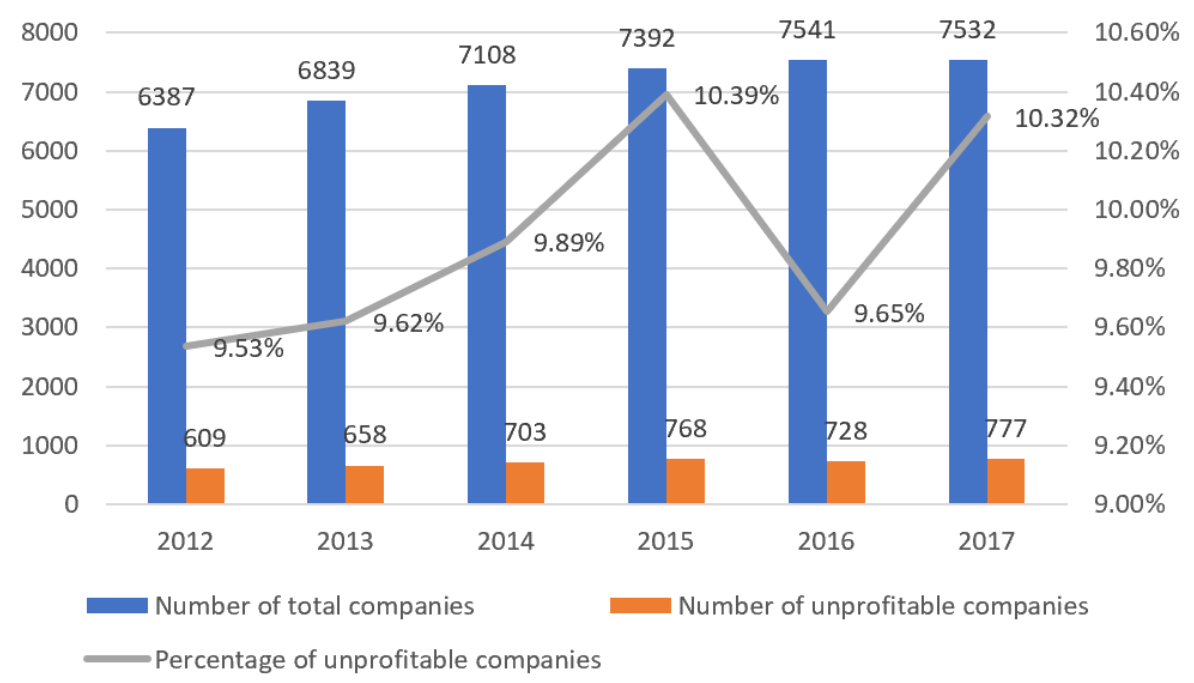

Figure 2. Number of pharmaceutical companies in China. Data resource: China National Bureau of Statistics, http://www.stats.gov.cn.

The international competitiveness of China's pharmaceutical industry has always been the focus of relevant departments of the Chinese government. A series of policies have been issued to improve the competitiveness of Chinese pharmaceutical companies, including the healthcare reform [13]. As shown in Figure 3, although the export of Chinese pharmaceutical products has maintained a certain growth rate, from 103.05 billion yuan in 2012 to 146.04 billion yuan in 2017, the annual growth rate has been quite unstable, with the highest in 2013, corresponding to $13.05 \%$, and the lowest in 2014, corresponding to only $1.65 \%$. It has been deeply affected by the fluctuation of the global trade environment in recent years, especially the Sino-US trade frictions. 


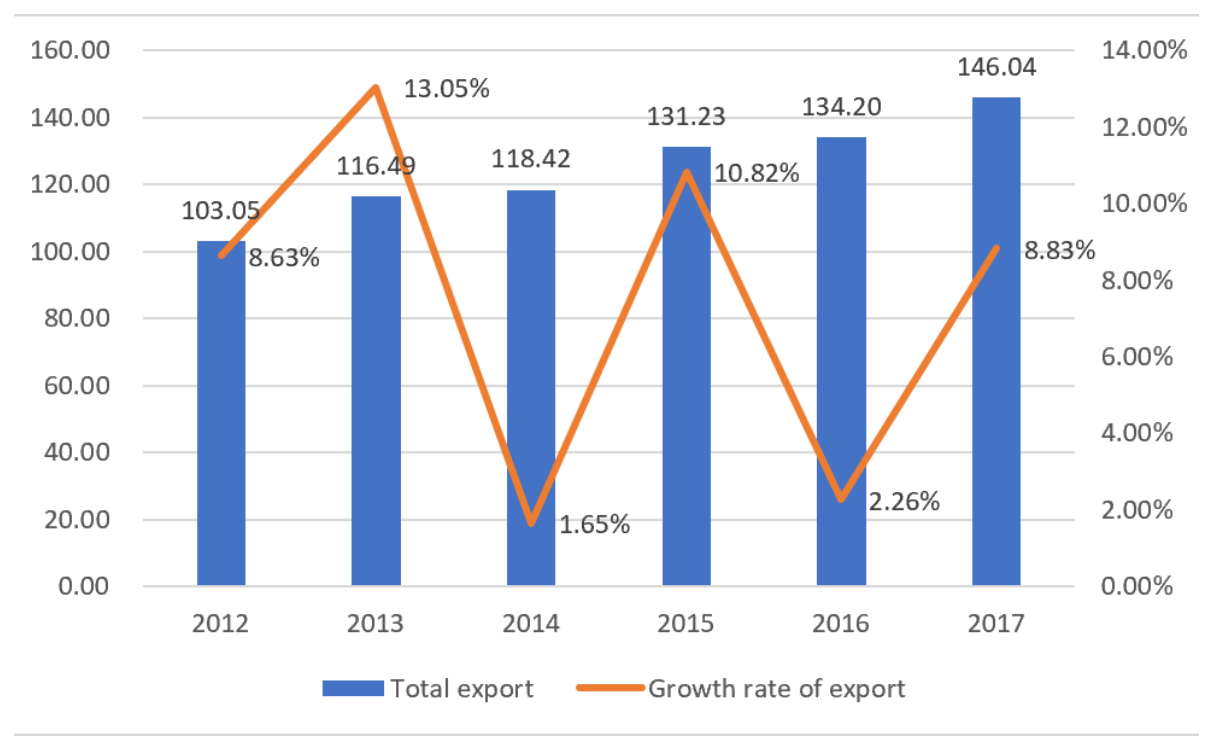

Figure 3. China's total exports of pharmaceutical products (billion yuan). Data resource: China National Bureau of Statistics, http://www.stats.gov.cn.

\subsection{Innovation of the Pharmaceutical Industry in China}

$R \& D$ expenditure is the most important way of innovation investment. Figure 4 shows the R\&D expenditure in China's pharmaceutical industry. The total investment in R\&D has shown a certain growth, from 28.33 billion yuan in 2012 to 53.42 billion yuan in 2017, with an increase of $88.56 \%$. However, the annual growth rate shows a certain downward trend. The growth rate in 2017 was the lowest in recent years, only $9.36 \%$.

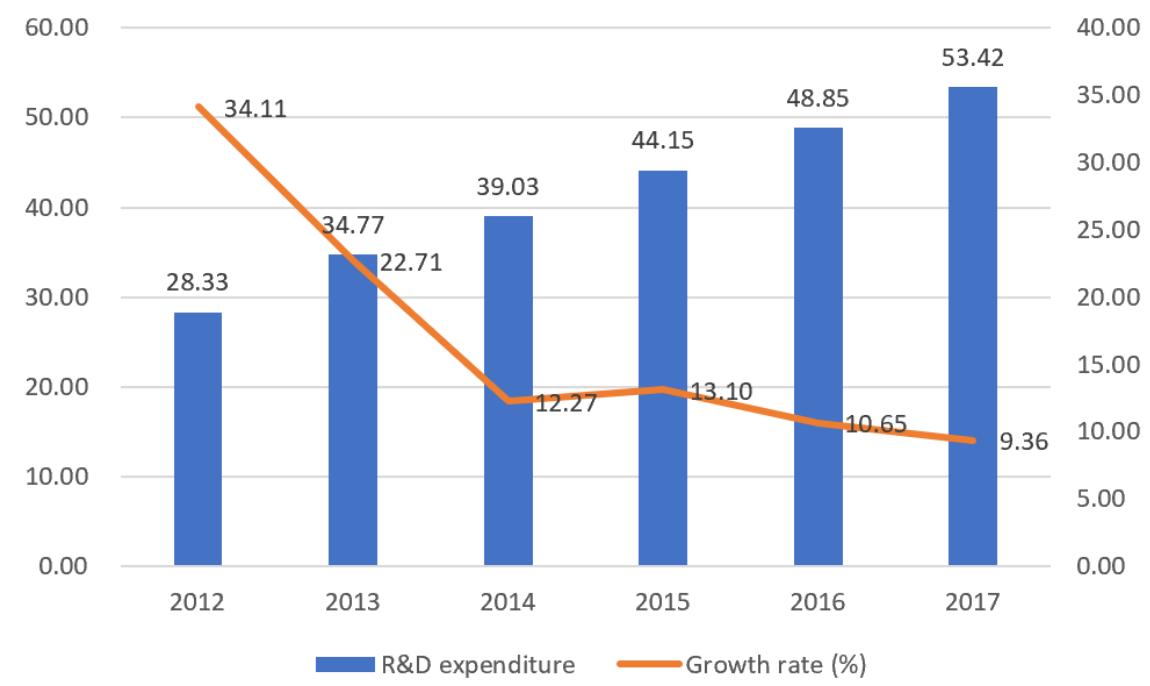

Figure 4. R\&D expenditure of the pharmaceutical industry in China (billion yuan). Data resource:

China National Bureau of Statistics, http://www.stats.gov.cn.

The number of patents is the most important indicator of innovation output. Figure 5 shows the number of patents in China's pharmaceutical industry in recent years. As can be seen from Figure 5, there was a big decline, from 19,354 patents in 2014 to 16,020 patents in 2015, with a decline rate of $17.23 \%$. The number of patents maintained a growth of about $11 \%$ in the following two years, reaching 19,878 patents in 2017, which was the highest in recent years. 


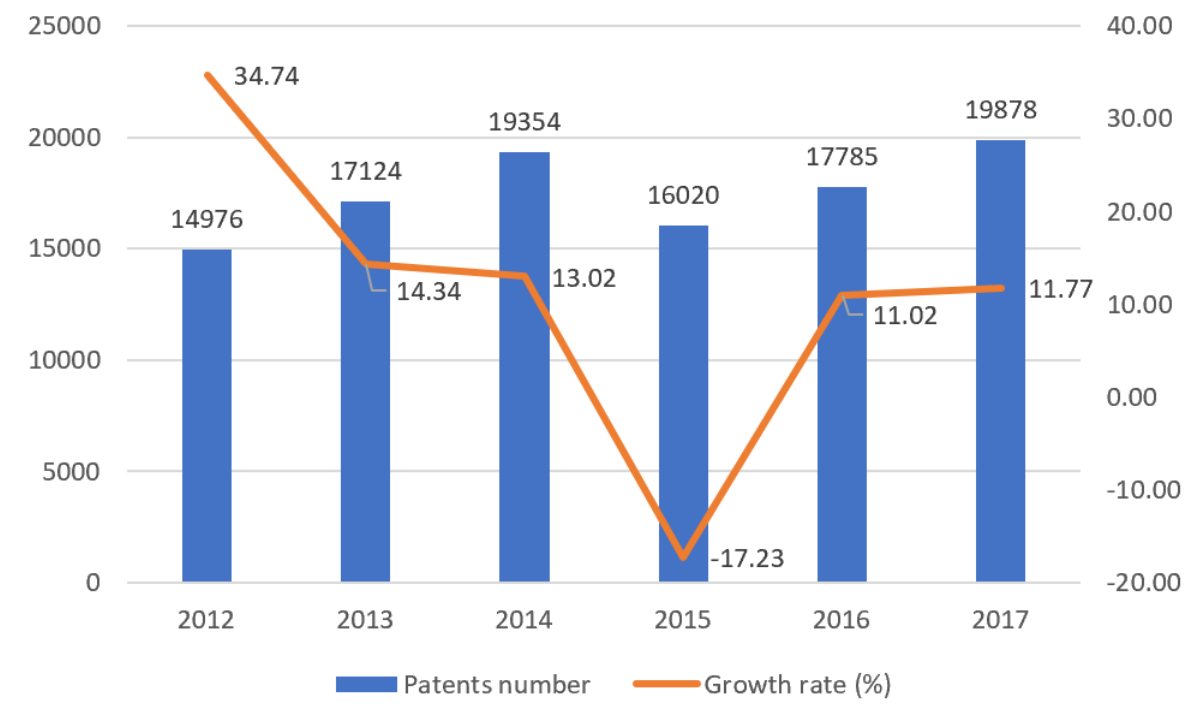

Figure 5. Number of patents of the pharmaceutical industry in China. Data resource: China National Bureau of Statistics, http://www.stats.gov.cn.

\subsection{Acquisitions of the Pharmaceutical Industry in China}

As can be seen from Figure 6, the acquisitions of Chinese pharmaceutical companies increased dramatically in 2015. The volume of acquisition deals increased from 191 in 2014 to 291 in 2015, while the total value of deals increased from $\$ 12,555$ million to $\$ 31,159$ million. In the following two years, the volume of acquisitions did not change much, but the total value of acquisitions declined considerably. The value of deals in 2017 was only \$17,115 million. However, in recent years, the cross-border acquisitions by Chinese pharmaceutical enterprises has witnessed a substantial increase, with the number of the deals increasing from only 8 in 2015 to 33 in 2017, and the total value of the deals increased from \$117 million to \$6362 million in 2017.

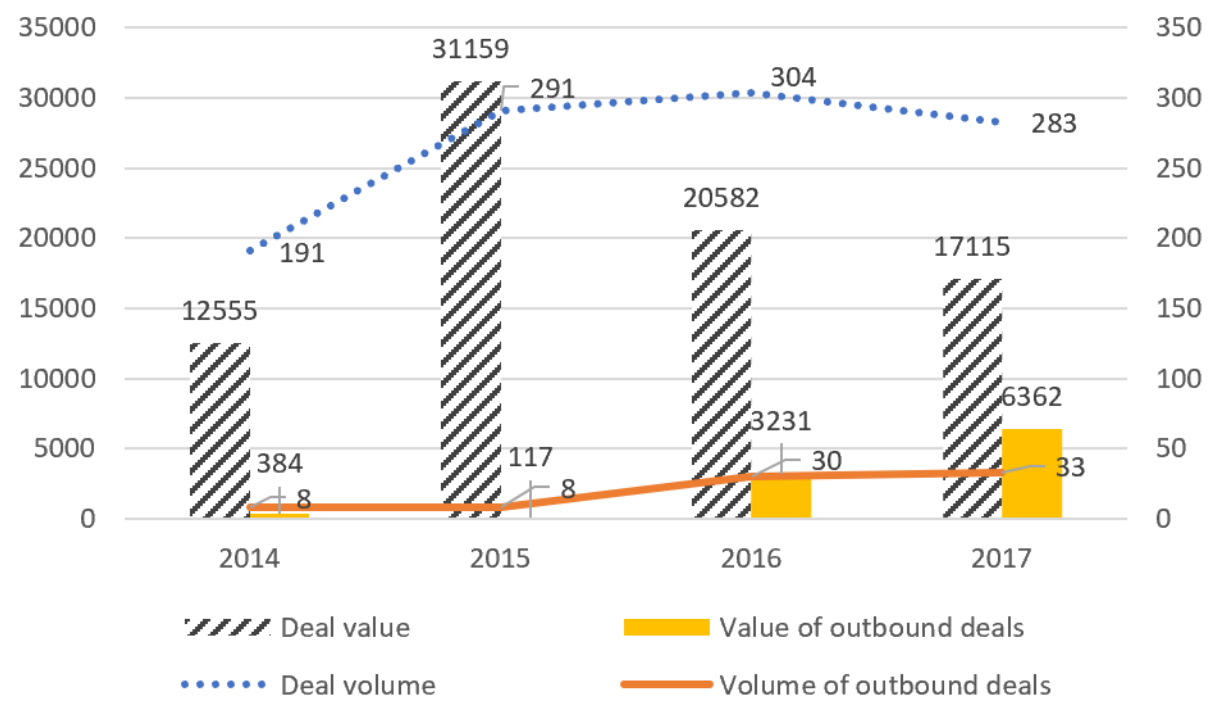

Figure 6. Deal value and volume of the pharmaceutical industry in China (million dollars). Data resource: www.pwccn.com.

China's pharmaceutical market is one of the largest pharmaceutical markets in the world [14]. From the above data, we can see that China's pharmaceutical industry has a large market base, fast growth and stability, and huge potential. With a huge number of enterprises, the competition is fierce and dynamic in the pharmaceutical industry. Innovation size in the pharmaceutical industry is large, 
but the growth rate has been slow recently. The output of innovation is not stable enough. Besides, the number of acquisitions has increased significantly compared with previous years but slowed down in the recent two years, while overseas acquisitions have increased substantially. Therefore, the innovation of the Chinese pharmaceutical industry and its role in acquisitions are of great practical significance.

\section{Literature Review and Hypotheses Proposition}

\subsection{Internal RED and Acquisition Performance}

The role of path dependence has been widely confirmed in organizational research, especially in the literature of technological innovation [15]. On the basis of the path dependence theory, we analyzed the impact of internal R\&D investment on acquisition performance. From the perspective of path dependence, internal R\&D may affect the whole process of acquisition, including choosing targets and post-acquisition integration. Firstly, although the internal R\&D of acquiring firms may be very important for firms to enhance certain aspects of knowledge and capabilities, path dependence resulting from internal R\&D leads to negative impacts on acquisition performance, such as increasing local search costs, resisting change, and not adapting to change [15]. In acquisition activities, the more internal R\&D the enterprise has done before, the more likely it is to be detrimental to its acquisition performance, such as improving local surveys and local search, change traps, and irreversible commitments to a certain type of research $[15,16]$. Because of the organizational inertia resulting from internal R\&D, it will affect the identification of target enterprises before acquisition [16]. In particular, companies with high pre-acquisition R\&D expenditure often engage in the development of specific technical areas rather than taking more time to find a target which can produce more benefits for them in the long run [15]. Some researchers have found that companies dedicated to existing $R \& D$ activities may rarely explore new technologies. This trend will make the acquisition of enterprises lack complementary considerations, thus reducing the potential of post-acquisition innovation. Secondly, internal R\&D activities shape a company-specific technology and research culture, which will lead to more complex and higher costs of technology integration for target companies to be acquired [17]. Sometimes, buyers need to forget some of their own knowledge in order to integrate the target technology. Therefore, the more internal knowledge and ability acquiring companies have, the more rigid they are in adopting new knowledge and abilities [16]. In addition, the internal R\&D activities of firms with high internal R\&D intensity will divert their attention and investment in post-acquisition integration to take advantage of external acquisition innovation opportunities, thus reducing the integration and synergy effects that may be achieved with the acquisitions [4]. Based on the above arguments, we propose Hypothesis 1 .

Hypothesis 1 (H1). Corporate Internal RED has a negative effect on acquisition performance in Chinese pharmaceutical industry.

\subsection{Moderating Effect of the Acquisition Motive}

According to the different motives behind an acquisition, acquisition can be divided into technical acquisition and non-technical acquisition [1]. From the perspective of the acquisition process, technical acquisition can effectively alleviate the negative impact of R\&D activities on acquisition performance, either before acquisition or after acquisition integration. On one hand, in technical acquisition activities, the expected goal of enterprise acquisition is to obtain potential synergies. Bena and Kai (2014) found that the synergistic effect is an important driving factor for enterprise acquisition [18]. Yu and Umashankar (2016) found that acquiring firms are more likely to choose target firms on the basis of R\&D synergies, that is, with a similar R\&D, and also on the basis of product synergies, that is, with complementary products [19]. On the other hand, whether the synergy effect can be produced depends mainly on whether the resources, such as technical knowledge and personnel, can be effectively optimized after acquisition, that is, whether the internal and external R\&D of the enterprise can be effectively integrated [20]. Compared with non-technological acquisition, enterprises acquire the 
technological resources of the target party through technological acquisition. As a result, the R\&D activities of enterprises have more large-scale economic effects and scope economic effects [10,21]. At the same time, managers in technical acquisition will devote more attention to the integration and utilization of technology resources, and enterprises in technical acquisition will focus more on the improvement of R\&D efficiency [7,22]. In addition, in the process of a non-technical acquisition, such as acquisition activities to obtain resources or expand the market share, the focus of the acquisition is not on the complementarity or synergy of technical resources of the two companies. Therefore, the acquisition process may break the conventions of the acquiring enterprises and reduce the efficiency of their original internal $R \& D$, thus affecting the performance improvement after acquisition. So, we propose Hypothesis 2:

Hypothesis 2 (H2). Acquisition motivation has a moderating effect on the relationship between internal RED and acquisition performance. That is, compared with non-technical acquisition, the negative effect of internal $R \mathcal{E D}$ on the acquisition performance of enterprises in technical acquisition will be significantly reduced.

\subsection{Moderating Role of Corporate Ownership}

Because of the particularity of the pharmaceutical industry, China's pharmaceutical industry is subjected to a strict policy control. Compared with private enterprises, China's state-owned pharmaceutical enterprises can get more support in policy and resources, while non-state-owned enterprises face more pressure in financing and taxation [23,24]. Considering the background of China's economic transformation and upgrading, most state-owned enterprises are facing the pressure of transformation and upgrading. Although state-owned enterprises have the support of national policies, their internal management problems are prominent. Unclear property rights and ineffective internal incentives make their acquisition and integration efficiency low, in general. Meanwhile, the management system of state-owned enterprises is rigid, their organizational flexibility is poor, and their R\&D activities are path-dependent and ineffective. Organizational inertia is more prominent, which makes it more difficult to adapt to and integrate external acquisitions [25,26], so the negative effect of internal R\&D on acquisition performance may be stronger. Non-state-owned enterprises have higher market sensitivity, clear responsibility for internal property rights, a relatively more effective management mechanism and incentive mechanism, which can improve the excessive path dependence of internal R\&D and effectively realize a synergy between internal $R \& D$ and external acquisition $[27,28]$. In conclusion, we propose Hypothesis 3:

Hypothesis 3 (H3). The corporate ownership has a moderating effect on the relationship between internal RED and acquisition performance. That is, compared with the acquisition by state-owned enterprises, the effect of internal RED on the acquisition performance of non-state-owned enterprises will be significantly improved.

We set some controlling variables in our framework based on related works, including Kohli and Mann (2012), Gubbi (2010), and Ekkayokkaya (2009) [29-31]. The framework is shown in Figure 7. 


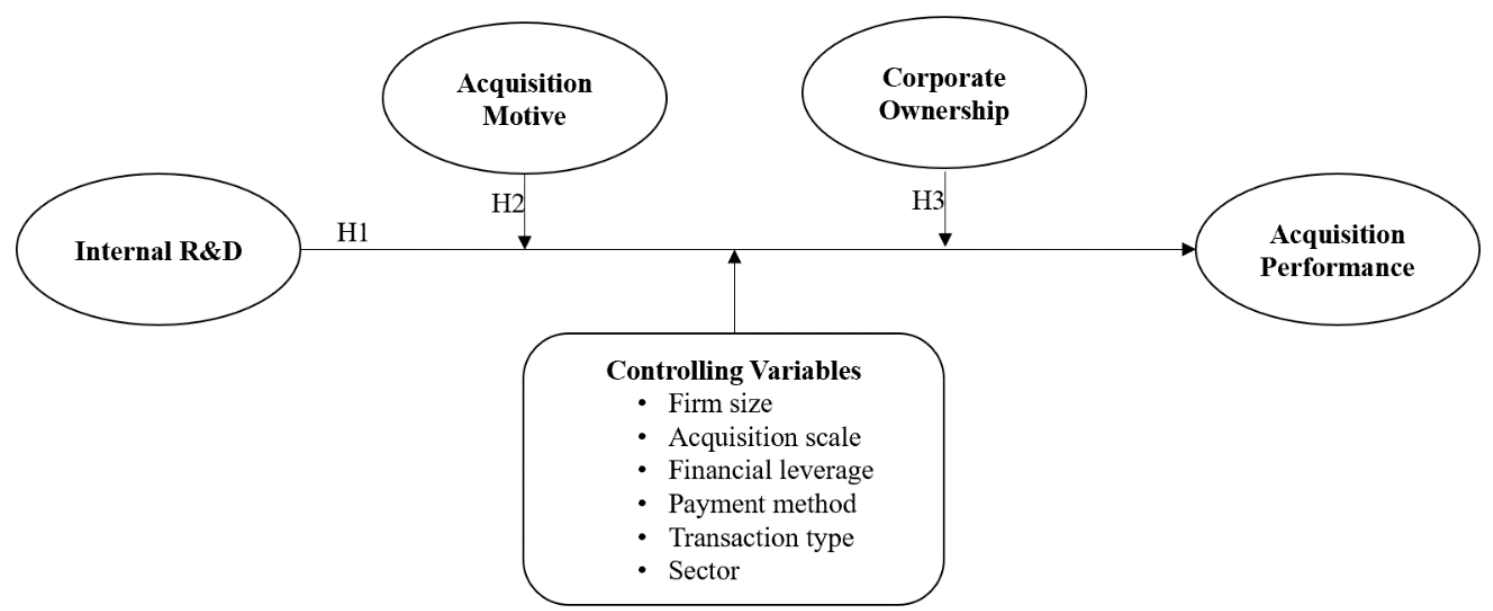

Figure 7. Framework of internal R\&D and acquisition performance.

\section{Methodology}

\subsection{Data}

This paper selected the acquisition events of listed companies in China from 2012 to 2016 as a research sample and excluded the following acquisition events: (1) unsuccessful acquisitions; (2) acquiring companies with less than $20 \%$ acquisition of shares; (3) acquisitions in which financial data disclosure was incomplete or unusual; (4) acquisitions carried out by Special Treated (ST) companies, which means the acquiring company had lost money for three consecutive years. Finally, 215 acquisitions were obtained. All data in this paper come from the CSMAR database, which is one of the major company databases in China, and from the public annual report of related listed companies.

\subsection{Variables}

1. Acquisition performance (PERF). In order to evaluate the acquisition performance more comprehensively, referring to the measurement methods of enterprise acquisition performance in Thanos et al. (2012) and Meglio and Risberg (2012) [32,33], this paper chose six indicators to reflect the status of enterprise acquisition performance more comprehensively: return on net assets, return on total assets, net sales interest rate, earnings per share, growth rate of operating income, and growth rate of net profit. Considering that internal R\&D has a time lag effect on corporate acquisition performance, according to Entezarkheir (2016) [34], this paper used performance indicators data corresponding to one year after the acquisition. The results of the Kaiser-Meyer-Olkin (KMO) test and Bartlett"s test are shown in Table 1, and those of the factor analysis of PERF are show in Table 2. In Table 1, we can see that the KMO was 0.725, with a $p$ value less than 0.001 , which shows that the six indicators were qualified for the factor analysis $[21,35,36]$. Table 2 shows that we could extract two components from the six indicators, which accounted for $77.872 \%$ of the whole explanation of the performance. Through factor analysis, a comprehensive indicator of acquisition performance was constructed, which included the two components. Component 1 was mainly composed of profitability and benefit indicators such as return on net assets, return on total assets, net sales interest rate, and earnings per share. Component 2 was mainly composed of growth rate of net profit and growth rate of operating income, which mainly reflected the development ability of the enterprises. The final measurement of acquisition performance was performed by multiplying the value of each component by the weighted average of its variance's contribution rate.

2. Internal R\&D (RD). Referring to Wang's (2011) practice [37], the data calculated from R\&D input/business income of enterprises in this year were used as a measure of the internal R\&D intensity of the enterprises, and the average values of internal $R \& D$ in two years before the 
acquisition, one year before the acquisition, and three years during the acquisition were selected as the final measurement value in this study.

3. Acquisition motive (TECH). According to Cefis and Marsili (2015) [38], this paper defined technology-based acquisition: the public reports of listed companies indicate that the acquisition of patented technology, core technology products, or other heterogeneous resources of the target enterprises belong to technology-based acquisition. At present, the literature mostly uses categorical variable to measure technical acquisitions. If there is technical acquisition, the value is 1. If there are other types of acquisition, i.e., non-technical acquisition, the value is 0 .

4. Corporate Ownership (OWNERSHIP). Referring to Li and Qian (2013) [39], the nature of the acquirer's enterprise is determined according to the actual controlling nature of the acquiring company provided in the financial report. The nature of the actual controlling person is judged by the nature of the largest shareholder. Enterprise nature is generally measured as a categorical variable. The value for a state-owned enterprise is 1 , and that for the non-state-owned enterprise is 0 .

5. Sector (SECTOR). Measured as a categorical variable, the value of Chinese pharmaceutical enterprises is 1 , and that of chemical-pharmaceutical enterprises is 0 .

6. Acquisition scale (SCALE). The acquisition scale is expressed by the ratio between the total value of the acquisitions and the total assets of the merged enterprise.

7. Financial leverage (LEV). Financial leverage is measured by the company's asset/liability ratio.

8. Firm size (SIZE). Measured by the logarithm of the total assets of the enterprise.

9. Payment method (PAYMENT). The value is 1 if the transaction is paid by cash; otherwise, the value is 0 .

10. Transaction type (RELATIVE). Whether the target is related to the acquiring firm in one way or another can have a major influence on the acquisition performance in China. For example, the target and the acquiring firm may have the same shareholder. So, for related transactions, we set the variable value to 1 , while we set it to 0 for non-related transactions.

Table 1. Kaiser-Meyer-Olkin (KMO) and Bartlett's test results. Df:, Sig.:

\begin{tabular}{ccc}
\hline \multicolumn{2}{c}{ Kaiser-Meyer-Olkin Measure of Sampling Adequacy } & 0.725 \\
\hline Bartlett's & Approx. Chi-Square & 798.475 \\
Test of & df & 15 \\
Sphericit & Sig. & 0.000 \\
\hline
\end{tabular}

Table 2. Results of factor analysis.

\begin{tabular}{ccccccc}
\hline & \multicolumn{3}{c}{ Initial Eigenvalues } & \multicolumn{2}{c}{ Extraction Sums of Squared Loadings } \\
\hline Component & Total & \% of Variance & Cumulative \% & Total & \% of Variance & Cumulative \% \\
\hline 1 & 3.096 & 51.594 & 51.594 & 3.096 & 51.594 & 51.594 \\
2 & 1.577 & 26.278 & 77.872 & 1.577 & 26.278 & 77.872 \\
3 & 0.612 & 10.208 & 88.080 & & & \\
4 & 0.376 & 6.263 & 94.344 & & & \\
5 & 0.262 & 4.365 & 98.709 & & & \\
6 & 0.077 & 1.291 & 100.000 & & & \\
\hline
\end{tabular}

\subsection{Models}

Following the study of Hagedoorn and Wang (2012) [21], we used multivariate regression analysis. We set three regression models for testing the above three hypotheses. Hypothesis 1 was tested by model 1. Furthermore, our sample of acquisitions was divided into two sub-samples according to acquisition motives and corporate ownership, to test the moderation effect. Hypothesis 2 was tested by Model 2 based on sub-samples of technical acquisitions and non-technical acquisition. Hypothesis 
3 was tested by model 3 based on sub-samples of state-owned acquiring firms and non-state-owned acquiring firms.

Model 1: PERF $=\alpha_{0}+\alpha_{1}$ RD $+\alpha_{2}$ TECH $+\alpha_{3}$ OWNERSHIP $+\alpha_{4}$ SIZE $+\alpha_{5}$ SCALE + $\alpha_{6}$ LEV $+\alpha_{7}$ PAYMENT $+\alpha_{8}$ RELATIVE $+\alpha_{9}$ SECTOR $+\varepsilon_{1}$

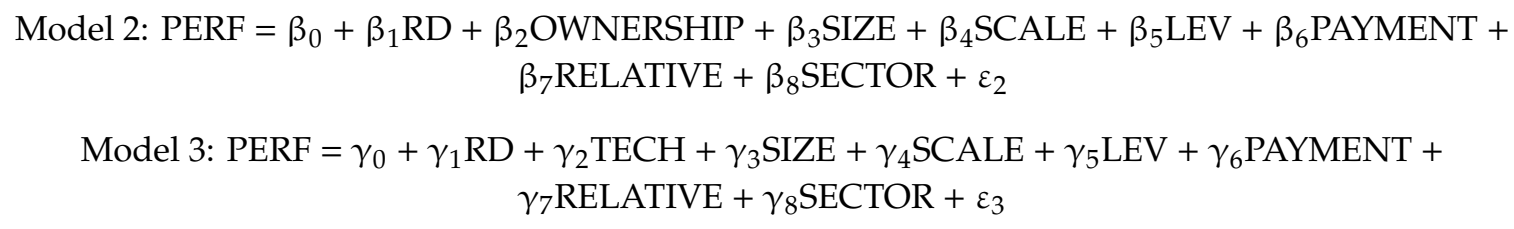

\section{Analysis and Results}

\subsection{Descriptive Analysis and Correlation Analysis}

Firstly, descriptive statistical analysis of the samples was carried out, as shown in Table 3. According to the motivation of acquisition (mean of TECH was 0.3023 , which means the value of TECH was 1 for $30.23 \%$ of the samples), there were 65 technical acquisitions and 150 non-technical acquisitions. According to the nature of enterprises (mean of OWNERSHIP was 0.1767, which means the value of OWNERSHIP was 1 for $17.67 \%$ of the samples), there were 38 state-owned-enterprise acquisitions and 177 non-state-owned-enterprises acquisitions. The correlation coefficients of each variable are shown in Table 4. From Table 4, it can be observed that there was a significant negative correlation between internal R\&D and acquisition performance, which supports our hypothesis that internal $R \& D$ has a negative impact on acquisition performance to a certain extent, but this needs to be further tested by regression analysis. In addition, we can see that there was a negative correlation between the nature of enterprises and the acquisition performance, which indicates that the acquisition performance of state-owned enterprises is relatively poor.

Table 3. Description of the variables. PERF: acquisition performance, RD: R\&D, TECH: acquisition motive, OWNETSHIP: corporate ownership, SIZE: firm size, SCALE: acquisition scale; LEV: financial leverage, PAYMENT: payment method, RELATIVE: transaction type, SECTOR: sector.

\begin{tabular}{ccccc}
\hline Variable & Min. & Max. & Mean & St.D \\
\hline PERF & -5.00 & 4.31 & 0.0000 & 0.73648 \\
RD & 0.09 & 18.56 & 3.8373 & 2.48776 \\
TECH & 0.00 & 1.00 & 0.3023 & 0.46034 \\
OWNERSHIP & 0.00 & 1.00 & 0.1767 & 0.38234 \\
SIZE & 8.40 & 10.74 & 9.5245 & 0.41870 \\
SCALE & 0.00 & 10.24 & 0.3319 & 1.04357 \\
LEV & 0.03 & 0.98 & 0.3377 & 0.18414 \\
PAYMENT & 0.00 & 1.00 & 0.7721 & 0.42046 \\
RELATIVE & 0.00 & 1.00 & 0.3349 & 0.47305 \\
SECTOR & 0.00 & 1.00 & 0.3256 & 0.46969 \\
\hline
\end{tabular}


Table 4. Coefficients and $p$-values of all variables in the correlation test.

\begin{tabular}{|c|c|c|c|c|c|c|c|c|c|}
\hline & PERF & RD & ТЕCH & OWNERSHIP & SIZE & SCALE & LEV & PAYMENT & RELATIVE \\
\hline $\begin{array}{l}\text { RD } \\
\text { Sig. }\end{array}$ & $\begin{array}{c}-0.174^{* *} \\
(0.011)\end{array}$ & & & & & & & & \\
\hline $\begin{array}{l}\text { TECH } \\
\text { Sig. }\end{array}$ & $\begin{array}{c}0.084 \\
(0.218)\end{array}$ & $\begin{array}{c}0.081 \\
(0.234)\end{array}$ & & & & & & & \\
\hline $\begin{array}{l}\text { OWNERSHIP } \\
\text { Sig. }\end{array}$ & $\begin{array}{c}-0.144 \text { ** } \\
(0.034)\end{array}$ & $\begin{array}{l}-0.254^{* * *} \\
(0.006)\end{array}$ & $\begin{array}{l}-0.066 \\
(0.335)\end{array}$ & & & & & & \\
\hline $\begin{array}{l}\text { SIZE } \\
\text { Sig. }\end{array}$ & $\begin{array}{c}0.005 \\
(0.936)\end{array}$ & $\begin{array}{l}-0.058 \\
(0.398)\end{array}$ & $\begin{array}{l}-0.055 \\
(0.421)\end{array}$ & $\begin{array}{c}0.220 * * * \\
(0.001)\end{array}$ & & & & & \\
\hline $\begin{array}{l}\text { SCALE } \\
\text { Sig. }\end{array}$ & $\begin{array}{c}0.445^{* * * *} \\
(0.000)\end{array}$ & $\begin{array}{l}-0.081 \\
(0.238)\end{array}$ & $\begin{array}{l}-0.008 \\
(0.902)\end{array}$ & $\begin{array}{c}-0.116^{*} \\
(0.089)\end{array}$ & $\begin{array}{c}-0.331^{* * *} \\
(0.000)\end{array}$ & & & & \\
\hline $\begin{array}{l}\text { LEV } \\
\text { Sig. }\end{array}$ & $\begin{array}{c}-0.294^{* * *} \\
(0.000)\end{array}$ & $\begin{array}{c}-0.219 * * * \\
(0.001)\end{array}$ & $\begin{array}{c}-0.227^{* * *} \\
(0.001)\end{array}$ & $\begin{array}{c}0.273^{* * *} \\
(0.000)\end{array}$ & $\begin{array}{c}0.241^{* * *} \\
(0.000)\end{array}$ & $\begin{array}{l}0.127 * \\
(0.063)\end{array}$ & & & \\
\hline $\begin{array}{l}\text { PAYMENT } \\
\text { Sig. }\end{array}$ & $\begin{array}{c}-0.133 * \\
(0.051)\end{array}$ & $\begin{array}{c}0.006 \\
(0.931)\end{array}$ & $\begin{array}{l}-0.029 \\
(0.676)\end{array}$ & $\begin{array}{l}-0.010 \\
(0.886)\end{array}$ & $\begin{array}{l}0.127^{*} \\
(0.063)\end{array}$ & $\begin{array}{l}-0.387^{* * *} \\
(0.000)\end{array}$ & $\begin{array}{l}-0.032 \\
(0.641)\end{array}$ & & \\
\hline $\begin{array}{l}\text { RELATIVE } \\
\text { Sig. }\end{array}$ & $\begin{array}{l}0.157 \text { * } \\
(0.021)\end{array}$ & $\begin{array}{l}-0.029 \\
(0.670)\end{array}$ & $\begin{array}{c}0.026 \\
(0.700) \\
\end{array}$ & $\begin{array}{c}0.033 \\
(0.631) \\
\end{array}$ & $\begin{array}{c}0.033 \\
(0.628)\end{array}$ & $\begin{array}{c}0.249^{* * *} \\
(0.000)\end{array}$ & $\begin{array}{c}0.031 \\
(0.653)\end{array}$ & $\begin{array}{c}-0.437^{* * *} \\
(0.000)\end{array}$ & \\
\hline $\begin{array}{l}\text { SECTOR } \\
\text { Sig. }\end{array}$ & $\begin{array}{l}0.126^{*} \\
(0.065)\end{array}$ & $\begin{array}{c}-0.379 * * * \\
(0.000)\end{array}$ & $\begin{array}{c}0.040 \\
(0.563)\end{array}$ & $\begin{array}{c}0.042 \\
(0.537)\end{array}$ & $\begin{array}{c}0.085 \\
(0.212)\end{array}$ & $\begin{array}{l}-0.051 \\
(0.459)\end{array}$ & $\begin{array}{c}0.037 \\
(0.587)\end{array}$ & $\begin{array}{l}0.117^{*} \\
(0.086)\end{array}$ & $\begin{array}{l}-0.009 \\
(0.892)\end{array}$ \\
\hline
\end{tabular}

The $p$-value of each coefficient is in brackets; ${ }^{*}$ indicates a significant effect at $10 \%, * *$ indicates a significant effect at $5 \%$, and ${ }^{* * *}$ indicates a significant effect at $1 \%$. 


\subsection{Regression Analysis of RED and Acquisition Performance}

The relationship between internal $R \& D$ and corporate acquisition performance was analyzed, and the results are shown in Table 5. As can be seen from Table 5, internal R\&D had a significant negative effect on acquisition performance, and Hypothesis 1 was supported.

Table 5. Regression results of Model 1.

\begin{tabular}{cccc}
\hline Variable & Coefficient & T-Value & Sig. \\
\hline RD & $-0.052^{* * *}$ & -2.708 & 0.007 \\
TECH & 0.074 & 0.793 & 0.429 \\
OWNERSHIP & $-0.216^{*}$ & -1.808 & 0.072 \\
SIZE & $0.441^{* * *}$ & 3.909 & 0.000 \\
SCALE & $0.377^{* * *}$ & 7.893 & 0.000 \\
LEV & $-1.049^{* * *}$ & -4.098 & 0.000 \\
PAYMENT & 0.046 & 0.393 & 0.694 \\
RELATIVE & 0.088 & 0.880 & 0.380 \\
SECTOR & 0.118 & 1.205 & 0.230 \\
\hline R-square & \multicolumn{3}{c}{0.340} \\
F-value & $11.756 * *$ \\
* indicates a significant effect at $10 \%$, and *** indicates a significant effect at $1 \%$.
\end{tabular}

\subsection{Test of Moderating Effect}

Because the motive of acquisition is a categorical variable, this paper examined the moderating effect by applying regression to grouped observations, and the results are shown in Table 6. Table 6 shows that the internal R\&D had a significant negative effect on the acquisition performance in the case of non-technical acquisitions but not in the case of technical acquisitions. This shows that compared with technical acquisitions, the negative effect of internal R\&D on the acquisition performance for non-technical acquisitions was stronger, and Hypothesis 2 was supported.

Table 6. Regression results of Model 2.

\begin{tabular}{ccccccc}
\hline & \multicolumn{2}{c}{ Non-Technical Acquisitions } & \multicolumn{2}{c}{ Technical Acquisitions } \\
\hline Variable & Coefficient & T-Value & Sig. & Coefficient & T-Value & Sig. \\
\hline RD & $-0.075^{* * *}$ & -3.084 & 0.002 & 0.023 & 0.836 & 0.407 \\
OWNERSHIP & $-0.253^{*}$ & -1.699 & 0.092 & 0.006 & 0.034 & 0.973 \\
SIZE & $0.473^{* * *}$ & 3.335 & 0.001 & $0.431^{* *}$ & 2.385 & 0.020 \\
SCALE & $0.388^{* * *}$ & 6.948 & 0.000 & $0.229^{* *}$ & 2.367 & 0.021 \\
LEV & $-1.197^{* * *}$ & -3.722 & 0.000 & $-1.020 * *$ & -2.487 & 0.016 \\
PAYMENT & -0.085 & -0.560 & 0.576 & 0.243 & 1.390 & 0.170 \\
RELATIVE & 0.090 & 0.705 & 0.482 & 0.145 & 1.012 & 0.316 \\
SECTOR & 0.133 & 1.027 & 0.306 & 0.169 & 1.289 & 0.203 \\
\hline R-square & \multicolumn{3}{c}{0.207} & $1.833 *$ \\
F-value & 0.391 \\
* indicates a significant effect at $10^{*} \%$ ** indicates a significant effect at $5 \%$, and *** indicates a significant effect at $1 \%$.
\end{tabular}

The moderating effect of firm nature was also tested by applying regression to grouped observations. The results are shown in Table 7. It can be found that both the internal R\&D of state-owned enterprises and that of non-state-owned enterprises had significant negative effects on the acquisition performance, but the absolute value of the coefficient for state-owned enterprises was larger, and Hypothesis 3 was supported. This shows that the internal R\&D of state-owned enterprises and non-state-owned enterprises had significant negative effects on the acquisition performance, but the negative effect for state-owned enterprises was stronger. 
Table 7. Regression results of Model 3.

\begin{tabular}{ccccccc}
\hline & \multicolumn{2}{c}{ State-Owned Acquiring Firms } & \multicolumn{2}{c}{ Non-State-Owned Acquiring Firms } \\
\hline Variable & Coefficient & T-Value & Sig. & Coefficient & T-Value & Sig. \\
\hline RD & $-0.098^{*}$ & -1.708 & 0.098 & $-0.048^{* *}$ & -2.296 & 0.023 \\
TECH & 0.117 & 0.587 & 0.561 & 0.064 & 0.599 & 0.550 \\
SIZE & $0.568^{* * *}$ & 2.869 & 0.008 & $0.418^{* *}$ & 3.201 & 0.002 \\
SCALE & 1.086 & 0.992 & 0.329 & $0.361^{* * *}$ & 7.036 & 0.000 \\
LEV & $-1.414^{* * *}$ & -3.480 & 0.002 & $-0.929^{* *}$ & -3.047 & 0.003 \\
PAYMENT & $0.607^{* *}$ & 2.490 & 0.019 & -0.093 & -0.656 & 0.513 \\
RELATIVE & 0.221 & 1.318 & 0.198 & 0.003 & 0.026 & 0.980 \\
SECTOR & 0.186 & 1.069 & 0.294 & 0.101 & 0.882 & 0.379 \\
\hline R-square & \multicolumn{5}{c}{0.318} & 0.314 \\
F-value & $0.663^{* * *}$ & & & 9.621 *** \\
\hline
\end{tabular}

\section{Discussion}

On the basis of acquisition cases of Chinese listed pharmaceutical companies, this paper empirically analyzed the relationship between technical acquisition, internal R\&D, and acquisition performance, obtaining the following results.

First, internal R\&D has a significant negative effect on acquisition performance in China's pharmaceutical industry. Although this result does not support some innovation studies that found a positive effect of $R \& D$ on corporate performance [1], this study is consistent with the view of the organizational inertia theory and path dependence theory [9]. For Chinese pharmaceutical enterprises, because of the large scale and long duration of R\&D investments, the behavior pattern of an enterprise will limit the identification of acquisition targets and the integration after acquisition, thus restricting the possible innovative results of R\&D investment [15]. Therefore, enterprises should consider the degree of complementarity with the target enterprises and the long-term development of the enterprises when making acquisitions. At the same time, pharmaceutical enterprises should consider asking third-party organizations to provide objective opinions on the acquisition under various possible conditions.

Secondly, acquisition motivation plays a moderating role. Compared with non-technical acquisitions, internal R\&D has no significant negative effect in technical acquisitions. This shows that technical acquisitions and internal R\&D can produce synergistic effects to some extent, which weakens the negative effect of internal R\&D on the acquisition performance. For Chinese pharmaceutical enterprises, in non-technical acquisitions, more attention should be paid to the potential negative effects of internal R\&D on the acquisition performance. Considering the whole process before and after acquisition, attention should be paid to the decision-making inertia and structural inertia of enterprises caused by R\&D, including the identification of constraints before acquisition and the structural rigidity after acquisition [19]. At the same time, the pharmaceutical companies should take technical acquisitions as far as possible to achieve complementarity and synergy between internal and external innovation modes [10].

Third, the nature of the enterprise has a moderating effect. Compared with state-owned enterprises, the negative effect of internal R\&D is reduced in the acquisitions of non-state-owned enterprises. For Chinese state-owned pharmaceutical enterprises, on one hand, more attention should be paid to avoiding the negative impact of internal R\&D in the acquisitions. Taking advantage of the synergistic effect of technical acquisition and internal R\&D appropriately can enhance the possible innovation and integration effect of acquisitions. On the other hand, state-owned pharmaceutical enterprises should pay more attention to the optimization of their own management mechanism and incentive system. They should try to avoid a rigid organizational structure in order to make organizational management and operation more scientific and effective $[25,26]$. For non-state-owned pharmaceutical enterprises, they should make full use of their flexible mechanism and market sensitivity to identify the acquisition 
targets with higher integration efficiency and achieve more effective post-acquisition integration through the collaboration of different innovative ways to achieve higher acquisition performance [21].

In addition, the results also show that the enterprise size has a significant positive effect in each regression model, indicating that firm size has a stable positive effect on the acquisition performance in the pharmaceutical industry. This result further supports the view of the scale effect in acquisition performance [3]. The larger the firm size is, the stronger its ability to deal with environmental dynamics, and the more stable it will be in the process of acquisition and integration [4]. Moreover, this result reflects that, because of the large scale and the long recovery time of innovation investments, larger enterprises are likely to make more investments in order to obtain innovation output [40]. This result also has a strong practical significance for the pharmaceutical industry.

\section{Conclusions}

Considering the results above, we can state the following conclusions.

Firstly, on the basis of the path dependence theory, this study explains the negative effect of internal R\&D on the acquisition performance of pharmaceutical enterprises. Although most theories, such as the resource-based view [41,42], believe that internal R\&D will help improve the performance and competitiveness of enterprises [21], this study further supports the organizational inertia caused by path dependence in acquisition activities; internal R\&D is more likely to hinder integration after acquisition, which is not conducive to the improvement of the acquisition performance.

Secondly, the results of this study support the relationship between internal and external innovation modes under the synergistic effect theory. Technological acquisition and internal R\&D can have a synergistic effect [21], improve organizational inertia and inertia caused by path dependence, promote the efficiency of internal R\&D production, and improve the acquisition performance.

Thirdly, the results of this study further show that the key institutional variable of firm nature plays a prominent role in the interpretation of corporate behavior and performance in China $[25,26]$ and further enriches the study of institutional theory on corporate behavior and performance in emerging market countries $[23,24]$.

On one hand, this study enriches the research on factors affecting the acquisition performance. On the other hand, it enriches the research in the field of innovation and the explanation of the effects of internal and external innovation on acquisition performance.

Author Contributions: Conceptualization, X.H.; Formal analysis, J.L.; Methodology, X.H.; Resources, J.L.; Supervision, Q.Y.; Writing—original draft, Q.Y.

Funding: This research was supported by the National Social Science Foundation of China under grant number 18BGL024, the Guangdong Provincial Natural Science Foundation of China under grant number 2018A0303130229, the Youth Innovative Talents Foundation of Guangdong Education Department of China under grant number 2017GWQNCX042, the Guangzhou Social Science Foundation of China under grant number 2019GZYB34 and 2017GZYB43.

Acknowledgments: Thank you for valuable comments and suggestions of the anonymous reviewers and the academic editors of Processes.

Conflicts of Interest: The authors declare no conflict of interest.

\section{References}

1. Deng, P. Why Do Chinese Firms Tend to Acquire Strategic Assets in International Expansion? J. World Bus. 2009, 44, 74-84. [CrossRef]

2. Luo, Y.; Xue, Q.; Han, B. How emerging Market governments promote outward FDI: Experience from China. J. World Bu. 2010, 45, 68-79. [CrossRef]

3. Shimizu, K.; Hitt, M.; Vaidyanath, D.; Pisano, V. Theoretical foundations of cross-border mergers and acquisitions: A review of current research and recommendations for the future. J. Int. Manag. 2004, 10, 307-353. [CrossRef] 
4. Muehlfeld, K.; Sahib, P.R.; Van Witteloosuijn, A. A Contextual Theory of Organizational Learning from failures and Successes: A Study of Acquisition Completion in the Global Newspaper Industry, 1981-2008. Strateg. Manag. J. 2012, 33, 938-964. [CrossRef]

5. Trichterborn, A.; Zu Knyphausen-Aufseß, D.; Schweizer, L. How to Improve Acquisition Performance: The Role of a Dedicated M\&A Function, M\&A Learning Process, and M\&A Capability. Strateg. Manag. J. 2016, $37,763-773$.

6. Sears, J.; Hoetker, G. Technological Overlap, Technological Capabilities, and Resource Recombination in Technological Acquisitions. Strateg. Manag. J. 2014, 35, 48-67. [CrossRef]

7. Rabier, M.R. Acquisition Motives and the Distribution of Acquisition Performance. Strateg. Manag. J. 2017, 38, 2666-2681. [CrossRef]

8. Ahuja, G.; Katila, R. Technological acquisitions and the innovation performance of acquiring firms: A longitudinal study. Strateg. Manag. J. 2001, 22, 197-220. [CrossRef]

9. Seru, A. Firm boundaries matter: Evidence from conglomerates and R\&D activity. J. Financ. Econ. 2014, 111, 381-405.

10. Hagedoorn, J.; Roijakkers, N.; Kranenburg, H. The formation of subsequent inter-firm R\&D partnerships between large pharmaceutical companies and small, entrepreneurial biotechnology firms-How important is interorganizational trust? Int. J. Technol. Manag. 2008, 44, 81-92.

11. Eisenhardt, K.M.; Martin, J.A. Dynamic capabilities: What are they? Strateg. Manag. J. 2000, 21, 1105-1121. [CrossRef]

12. Rothaermel, F.T.; Hess, A.M. Building dynamic capabilities: Innovation driven by individual-, firm-, and network-level effects. Organ. Sci. 2007, 18, 898-921. [CrossRef]

13. Di Tommaso, M.R.; Huang, M.; Yue, Q.; Pollio, C. The Chinese TCM Industry: Growth, Changes and Policies. In Healthcare Policies and Systems in Europe and China. Comparisons and Synergies; Mucelli, A., Francesca, S., Eds.; World Scientific Press: Singapore, 2018.

14. Di Tommaso, M.R.; Bonnini, S.; Yue, Q. Focusing on the Chinese Health Industry: An empirical enquiry on the TCM listed firms. Is Large and Private Beautiful? Int. J. Healthc. Technol. Manag. 2017, 16, 77-94. [CrossRef]

15. Benner, M.J.; Tushman, M. Process Management and Technological Innovation: A Longitudinal Study of the Photography and Paint Industries. Adm. Sci. Q. 2002, 47, 676-707. [CrossRef]

16. Barton, L. Core Capabilities and Core Rigidities: A Paradox in Managing New Product Development. Strateg. Manag. J. 1992, 13, 111-125. [CrossRef]

17. Nagarajan, A.; Mitchell, W. Evolutionary Diffusion: Internal and External Methods Used to Acquire Encompassing, Complementary, and Incremental Technological Changes in the Lithotripsy Industry. Strateg. Manag. J. 1998, 19, 1063-1077. [CrossRef]

18. Bena, J.; Kai, L.I. Corporate Innovations and Mergers and Acquisitions. J. Financ. 2014, 69, $1923-1960$. [CrossRef]

19. Yu, Y.; Umashankar, N.; Rao, V.R. Choosing the Right Target: Relative Preferences for Resource Similarity and Complementarity in Acquisition Choice. Strateg. Manag. J. 2016, 37, 1808-1825. [CrossRef]

20. Schweizer, L. Organizational integration of acquired biotechnology companies into pharmaceutical companies: The need for a hybrid approach. Acad. Manag. J. 2005, 48, 1051-1074. [CrossRef]

21. Hagedoorn, J.; Wang, N. Is there complementarity or substitutability between internal and external R\&D strategies? Res. Policy 2012, 41, 1072-1083.

22. Chen, S.F.S. The motives for international acquisitions: Capability procurements, strategic considerations, and the role of ownership structures. J. Int. Bus. Stud. 2008, 39, 454-471. [CrossRef]

23. Luo, Y.; Zhao, H.; Wang, Y.; Xi, Y. Venturing abroad by emerging market enterprises. Manag. Int. Rev. 2011, 51, 433. [CrossRef]

24. Warner, M.; Sek Hong, N.; Xiaojun, X. 'Late development' experience and the evolution of transnational firms in the People's Republic of China. Asia Pac. Bus. Rev. 2004, 10, 324-345. [CrossRef]

25. Liang, X.; Lu, X.; Wang, L. Outward internationalization of private enterprises in China: The effect of competitive advantages and disadvantages compared to home market rivals. J. World Bus. 2012, 47, $134-144$. [CrossRef]

26. Lin, J.Y.; Tan, G. Policy burdens, accountability, and the soft budget constraint. Am. Econ. Rev. 1999, 89, 426-431. [CrossRef] 
27. Feldman, M.P.; Kelley, M.R. The ex-ante assessment of knowledge spillovers: Government R\&D policy, economic incentives and private firm behavior. Res. Policy 2006, 35, 1509-1521.

28. Kleer, R. Government R\&D Subsidies as a Signal for Private Investors. Res. Policy 2010, 39, 1361-1374.

29. Kohli, R.; Mann, B.J.S. Analyzing Determinants of Value Creation in Domestic and Cross Border Acquisitions in India. Int. Bus. Rev. 2012, 21, 998-1016. [CrossRef]

30. Gubbi, S.R.; Aulakh, P.S.; Ray, S.; Sarkar, M.B.; Chittoor, R. Do International Acquisitions by Emerging-Economy Firms Create Shareholder Value the Case of Indian Firms. J. Int. Bus. Stud. 2010, 41, 397-418. [CrossRef]

31. Ekkayokkaya, M.; Holmes, P.; Paudyal, K. The Euro and The Changing Face of European Banking: Evidence from Mergers and Acquisitions. Eur. Financ. Manag. 2009, 15, 451-476. [CrossRef]

32. Thanos, I.C.; Papadakis, V. Unbundling Acquisition Performance: How Do They Perform and How Can This Be Measured; Oxford University Press: Oxford, UK, 2012.

33. Meglio, O.; Risberg, A. The Measurement of M\&A Performance-A Systematic Narrative Literature Review. Scand. J. Manag. 2011, 27, 418-433.

34. Entezarkheir, M.; Moshiri, S. Is Innovation a Factor in Merger Decisions? Evidence from a Panel of U.S. Firms; Social Science Electronic Publishing: Waltham, MA, USA, 2016.

35. Deligiannis, A.; Sidiropoulos, G.; Chalikias, M.; Kyriakopoulos, G. The Impact of Mergers and Acquisitions on Corporate Culture and Employees: The Case of Aegean \& Olympic Air. Acad. Strateg. Manag. J. 2018, 17, $1-13$.

36. Kaiser, H.F. An index of factorial simplicity. Psychometrika 1974, 39, 31-36. [CrossRef]

37. Wang, J. Discussion on the Relationship between Green Technological Innovation and System Innovation. Eng. Procedia 2011, 5, 2352-2357.

38. Cefis, E.; Marsili, O. Crossing the Innovation Threshold through Mergers and Acquisitions. Res. Policy 2015, 44, 698-710. [CrossRef]

39. Li, J.; Qian, C. Principal Principal Conflicts Under Weak Institutions: A Study of Corporate Takeovers in China. Strateg. Manag. J. 2013, 34, 498-508. [CrossRef]

40. Nadolska, A.; Barkema, H.G. Good Learners: How to Management Teams Affect the Success and Frequency of Acquisitions. Strateg. Manag. J. 2014, 35, 25. [CrossRef]

41. Barney, J. Firm resources and sustained competitive advantage. J. Manag. 1991, 17, 99-120. [CrossRef]

42. Teece, D.J.; Pisano, G.; Shuen, A. Dynamic capabilities and strategic management. Strateg. Manag. J. 1997, 18, 509-533. [CrossRef]

(C) 2019 by the authors. Licensee MDPI, Basel, Switzerland. This article is an open access article distributed under the terms and conditions of the Creative Commons Attribution (CC BY) license (http://creativecommons.org/licenses/by/4.0/). 